\title{
EFFECT OF RELATIONSHIP DYNAMICS AND ISOLATION ON MENTAL HEALTH OF INFERTILE WOMEN
}

\author{
Rabia Zonash Mir', Seema Zahid', Saima Ehsan ${ }^{\prime 凶}$
}

\begin{abstract}
OBJECTIVE: To explore the effect of relationship dynamics and isolation on mental health of infertile women.

METHODS: This correlational study was conducted on pregnant women from January 2018 to December 2018 . About I 50 infertile women in the age range I 8 to 50 years were enrolled from selected infertility centers of Rawalpindi and Islamabad, Pakistan. Three different scales, like Relationship Dynamics Scale (RDS), Revised UCLA Loneliness Scale (RULS) and Mental Health Inventory $(\mathrm{MHI})$, were used in this study. Multiple Regression, Pearson Correlation Matrix and T-test were applied on study variables using SPSS v.21.0.
\end{abstract}

RESULTS: Infertile women with uterus issue are higher on relationship dynamics scale $(M=16.16 \pm 3.18)$, UCLA loneliness scale $(M=50.87 \pm 8.80)$, and on components of mental health inventory e.g., positive affect $(M=17.29 \pm 3.58)$. Infertile women with tube issues are higher on $\mathrm{MHI}$, e.g., anxiety $(M=|8.9| \pm 3.47)$, depression $(M=\mid 5.58 \pm 3.34)$ and behavioral control $(M=17.83 \pm 2.55)$. Linear regression analysis showed significant negative effect of relationship dynamic scale that brought about $32.5 \%$ change in anxiety, $4 \%$ in depression, $4.4 \%$ change in behavior control, and $5.7 \%$ change in positive affect which are four major components of mental health $(p<.00 \mathrm{I})$. Loneliness scale also showed negative effect on components of mental health that brought about $23.4 \%$ variance in anxiety, $2.2 \%$ in depression, $12.8 \%$ in behavior control, and $16.8 \%$ in positive among infertile women $(\mathrm{p}<.00 \mathrm{I})$.

CONCLUSION: Infertile women having more relationship dynamics were found to be low on depression, anxiety, behavior control and positive affect. Infertile women facing more isolation have less positive affect and behavior control.

KEY WORDS: Relationship dynamics (Non-MeSH); Isolation (Non-MeSH); Infertile Women (Non-MeSH); Gynecological Issues (Non-MeSH); Anxiety (MeSH); Depression (MeSH); Behavioral Control (MeSH).

THIS ARTICLE MAY BE CITED AS: Mir RZ, Zahid S, Ehsan S. Effect of relationship dynamics and isolation on mental health of infertile women. Khyber Med Univ J 2020; I2(3):238-44. DOI: 10.35845/kmuj.2020.19655.

\section{INTRODUCTION}

An interpersonal relationship is a
close, deep and strong affiliation or
association between two or more
people. The counter part of a
relationship is isolation. Isolation refers
to lack of communication or social
distance from other people.' The
isolation may occur due to voluntary
withdrawal from close relationships and
can be a significant feature of different
disorders specifically depression.
Mental health is an important indicator of global functioning of an individual. According to World Health Organization (WHO), a mentally healthy person is capable of realizing his or her potentials, coping with daily life stressors, managing relationships, working productively and contributing to his or her society.

Various other factors which may affect an individual's mental health and social relationships, infertility is becoming the
I. Foundation University, Rawalpindi Campus, Rawalpindi, Pakistan.

2. International Islamic University, Islamabad, Pakistan..

Email $^{\bowtie}:$ rabi_123_mir@yahoo.com

Contact \# : +92-332-5875692

$\begin{array}{ll}\text { Date Submitted: } & \text { August 29, } 2019 \\ \text { Date Revised: } & \text { July } 25,2020 \\ \text { Date Accepted: } & \text { August 24, } 2020\end{array}$

focus of researchers' attention. Infertility refers to inability of a person to reproduce naturally. The reports of the International Committee for Monitoring Assisted Reproductive Technology (ICMART) and the WHO identify the criteria set for infertility. These reports hold that the infertility is the failure of a couple to conceive after 12 months of unprotected pregnancy attempts. ${ }^{3}$ It is estimated that I in 8 couples (or 12\% of married women) are suffering from infertility issues. Patient of infertility often report struggling with isolation, depression, fretfulness, and loss of control. Volgsten and colleagues also highlighted that about $31 \%$ of infertile women experienced psychiatric symptoms in which depression was most common. ${ }^{5}$ The prevalence statics show that $60-80$ million people are affected by infertility every year globally. It is revealed that the number of infertile couples has been increased from 12.0 million in 1990 to 48.5 million in 2010. The estimates in this context also showed that in $35 \%$ to $40 \%$ cases, man is infertile and by the same token $35 \%$ to $40 \%$ cases woman is infertile while $30 \%$ to $40 \%$ of the cases are related to several other factors. ${ }^{6,7}$ Although the consequences of fertility are vast and the impact created by it may vary depending upon many factors, yet, its impact created on the relationship of a couple is most commonly studied dimension. ${ }^{8}$ A vast majority of studies conducted on infertile couples reveal that the stress and struggle while trying to conceive is 
TABLE I: CORRELATION MATRIX AMONG RELATIONSHIP DYNAMICS, ISOLATION AND MENTAL HEALTH COMPONENTS $(\mathrm{N}=150)$

\begin{tabular}{|c|c|c|c|c|c|c|}
\hline & Relationship Dynamics & Isolation & Anxiety & Depression & Behavior control & \begin{tabular}{|l|} 
Positive affect \\
\end{tabular} \\
\hline Relationship Dynamics $^{\#}$ & - & $0.525^{*} *$ & $-0.570 * *$ & $-0.200 *$ & $-0.210 *$ & $-0.238 * *$ \\
\hline Isolation $^{\# \#}$ & & - & $-0.483 * *$ & -0.149 & $-0.358 * *$ & $-0.409 * *$ \\
\hline Anxiety ${ }^{\# \# \#}$ & & & - & $0.446 * *$ & $0.283 * *$ & $0.200 *$ \\
\hline Depression $^{\text {s }}$ & & & & - & $0.257^{* *}$ & $-0.215 * *$ \\
\hline Behavior control $^{\$}$ & & & & & - & 0.357 *** \\
\hline Positive affect ${ }^{\$}$ & & & & & & - \\
\hline $\mathrm{a}^{* * * * *}$ & 0.70 & 0.80 & 0.39 & 0.53 & 0.60 & 0.52 \\
\hline
\end{tabular}

\#Relationship Dynamics Scale, \#\#Revised UCLA Loneliness Scale, \#\#\#Mental Health Inventory, \$Mental Health Inventory, ${ }^{p}<0.05, *{ }^{*} p<0.01, * * *$ Alpha Reliability

TABLE II: MENSTRUAL CYCLE ISSUES ON RELATIONSHIP DYNAMICS, ISOLATION AND MENTAL HEALTH COMPONENTS ( $N=150)$

\begin{tabular}{|c|c|c|c|c|c|c|c|}
\hline \multirow{3}{*}{ Variables } & \multicolumn{2}{|c|}{ Menstrual issues } & \multirow{3}{*}{$\mathbf{t}$} & \multirow{3}{*}{ p-value } & \multicolumn{2}{|c|}{$\mathbf{9 5 \%}$ Confidence Interval } & \multirow{3}{*}{ Cohen's d } \\
\hline & Yes $(n=71)$ & No $(n=79)$ & & & Lower & Upper & \\
\hline & Mean \pm SD & Mean \pm SD & & & Limit & Limit & \\
\hline Relationship Dynamics" & $15.73 \pm 2.80$ & $14.35 \pm 3.74$ & 2.52 & $0.01 * *$ & 0.300 & 2.45 & 0.41 \\
\hline Isolation $^{\# \#}$ & $49.78 \pm 7.43$ & $48.59 \pm 10.7$ & 0.784 & 0.43 & $-1.8 \mid$ & 4.20 & 0.12 \\
\hline Anxiety ${ }^{\# \# \#}$ & $16.90 \pm 3.30$ & $18.11 \pm 4.06$ & -1.9 & $0.04 *$ & $-2.4 I$ & -0.008 & 0.32 \\
\hline Depression $^{5}$ & $13.81 \pm 4.00$ & $14.15 \pm 3.04$ & -0.58 & 0.56 & -1.47 & 0.805 & 0.09 \\
\hline Behavior control $^{\$}$ & $16.59 \pm 2.59$ & $15.63 \pm 2.94$ & 2.10 & $0.03 *$ & 0.059 & 1.85 & 0.34 \\
\hline Positive affect ${ }^{\$}$ & $17.29 \pm 3.63$ & $17.00 \pm 3.56$ & 0.502 & 0.61 & -.867 & 1.45 & 0.08 \\
\hline
\end{tabular}

\#Relationship Dynamics Scale, \#\#Revised UCLA Loneliness Scale, \#\#\#Mental Health Inventory, \$Mental Health Inventory, ${ }^{*} p<0.05$, **p $<0.01$ Independent sample t-test.

TABLE III: HISTORY OF MISCARRIAGE ON RELATIONSHIP DYNAMICS, ISOLATION AND MENTAL HEALTH COMPONENTS ( $N=150)$

\begin{tabular}{|c|c|c|c|c|c|c|c|}
\hline \multirow{3}{*}{ Variables } & \multicolumn{2}{|c|}{ Menstrual issues } & \multirow{3}{*}{$\mathbf{t}$} & \multirow{3}{*}{ p-value } & \multicolumn{2}{|c|}{$95 \%$ Confidence Interval } & \multirow{3}{*}{ Cohen's d } \\
\hline & Yes $(n=7 I)$ & No $(n=79)$ & & & Lower & Upper & \\
\hline & Mean \pm SD & Mean \pm SD & & & Limit & Limit & \\
\hline Relationship Dynamics $^{\#}$ & $15.63 \pm 3.37$ & $14.67 \pm 3.37$ & 1.66 & 0.09 & -0.18 & 2.10 & 0.28 \\
\hline Isolation $_{\# \#}^{\#}$ & $49.73 \pm 7.76$ & $48.85 \pm 10.0$ & 0.546 & 0.58 & -2.28 & 4.03 & 0.09 \\
\hline Anxiety $^{\# \# \#}$ & $17.15 \pm 3.06$ & $17.74 \pm 4.08$ & -0.91 & 0.36 & -1.86 & 0.685 & 0.16 \\
\hline Depression $^{5}$ & $13.15 \pm 3.58$ & $14.43 \pm 3.42$ & -2.1 & $0.03 *$ & -2.46 & -0.105 & 0.36 \\
\hline Behavior control $^{\$}$ & $15.92 \pm 2.48$ & $16.17 \pm 2.98$ & -0.51 & 0.60 & -1.20 & -0.706 & 0.09 \\
\hline Positive affect ${ }^{\$}$ & $16.86 \pm 3.53$ & $17.28 \pm 3.62$ & -0.68 & 0.49 & -1.64 & .0799 & 0.11 \\
\hline
\end{tabular}

the major factor which influences the quality of relationship between couples. $^{9}$

The term 'relationship' refers to a dynamic process. Experts agree that strong and healthy relationship create positive impact on mental health and overall aspects of life while problematic relationships or social isolation may cause severe damage to mental health and overall life quality of an individual." The comparisons made between people with healthier relationships and those having relationship distress revealed that people having healthier and happier relationships are mentally stable and strong than those suffering from relationships distress. The individuals with weaker relationships or social isolation are twice as likely to suffer from mental disorders and substance use. It is evident from existing literature that weak or disrupted relationships may lead to isolation and isolation consequently may lead to different mood and anxiety disorders. It can be concluded that relationship distress and isolation creates significant negative impact on overall life of a person. $^{12}$

The literature reveals that our survival is largely dependent upon our social networks i.e. families, friends, spouse, communities etc. a recent study was conducted on women going trough infertility treatment out of the sample 174 women $39 \%$ were diagnosed with major depressive disorder. ${ }^{13}$ One of the largest study on infertility containing sample of 352 women and 274 men was collected from infertility centers of northern California. The study revealed that $56 \%$ of the women and $32 \%$ of the men experienced symptoms of depression whereas, anxiety symptoms existed in $76 \%$ of the women and $61 \%$ of the men. ${ }^{14}$ A recent study by Xu et al ${ }^{15}$ revealed through their investigation that socially isolated people suffer from great mental health problems. Another study conducted by Lynch et al $^{16}$ investigated infertility crisis in women 
EFFECT OF RELATIONSHIP DYNAMICS AND ISOLATION ON MENTAL HEALTH OF INFERTILE WOMEN

TABLE IV: YEARS OF TREATMENT DIFFERENCE ON RELATIONSHIP DYNAMICS, ISOLATION AND MENTAL HEALTH COMPONENTS $(N=150)$

\begin{tabular}{|c|c|c|c|c|c|c|}
\hline \multirow{3}{*}{ Variables } & $\begin{array}{l}\text { No treatment } \\
\text { Years }\end{array}$ & $\begin{array}{c}2-5 \\
\text { Years }\end{array}$ & $\begin{array}{l}6-10 \\
\text { Years }\end{array}$ & $\begin{array}{l}\text { II-15 } \\
\text { Years }\end{array}$ & \multirow{3}{*}{$\mathbf{F}$} & \multirow{3}{*}{$\eta^{2}$} \\
\hline & $(n=37)$ & $(n=79)$ & $(n=25)$ & $(n=15)$ & & \\
\hline & Mean \pm SD & Mean \pm SD & Mean \pm SD & Mean \pm SD & & \\
\hline Relationship Dynamics ${ }^{\#}$ & $14.62 \pm 3.60$ & $15.09 \pm 3.47$ & $14.88 \pm 3.49$ & $|5.73 \pm 2.2|$ & 0.41 & 0.14 \\
\hline Isolation $^{\# \#}$ & $49.32 \pm 12.00$ & $49.65 \pm 7.61$ & $48.28 \pm 10.34$ & $47.80 \pm 7.91$ & 0.25 & 0.33 \\
\hline Anxiety ${ }^{\# \# \#}$ & $17.9 \mid \pm 4.58$ & $|7.42 \pm 3.3|$ & $19.00 \pm 3.52$ & $14.73 \pm 4.49$ & $4.47 * *$ & 0.15 \\
\hline Depression $^{5}$ & $13.70 \pm 3.69$ & $14.26 \pm 3.46$ & $15.08 \pm 3.52$ & $11.60 \pm 2.26$ & $3.49 * *$ & 0.11 \\
\hline Behavior control $^{\$}$ & $15.97 \pm 3.17$ & $16.20 \pm 2.86$ & $16.04 \pm 2.55$ & $15.86 \pm 2.19$ & 0.95* & 0.07 \\
\hline Positive affect ${ }^{\$}$ & $17.37 \pm 3.80$ & $17.06 \pm 3.01$ & $16.80 \pm 4.62$ & $|5.46 \pm 4.0|$ & 0.17 & 0.19 \\
\hline
\end{tabular}

\#Relationship Dynamics Scale, \#\#Revised UCLA Loneliness Scale, \#\#\#Mental Health Inventory, SMental Health Inventory, ${ }^{*} p<0.05$, ** $p<0.01$, ANOVA

TABLE V: GYNECOLOGICAL ISSUES DIFFERENCE ON RELATIONSHIP DYNAMICS, ISOLATION AND MENTAL HEALTH COMPONENTS $(\mathbf{N}=150)$

\begin{tabular}{|c|c|c|c|c|c|c|}
\hline \multirow{3}{*}{ Variables } & No issues & $\begin{array}{c}\text { Ectopic } \\
\text { Pregnancy }\end{array}$ & Uterus & Tube & \multirow{3}{*}{$\mathbf{F}$} & \multirow{3}{*}{$\eta^{2}$} \\
\hline & $(n=74)$ & $(n=9)$ & $(n=55)$ & $(n=12)$ & & \\
\hline & Mean \pm SD & Mean \pm SD & Mean \pm SD & Mean \pm SD & & \\
\hline Relationship Dynamics ${ }^{\#}$ & $|4.4| \pm 3.52$ & $14.33 \pm 2.29$ & $16.16 \pm 3.18$ & $13.83 \pm 2.97$ & $3.65 * *$ & .06 \\
\hline Isolation $^{\# \#}$ & $48.24 \pm 10.57$ & $48.55 \pm 3.64$ & $50.87 \pm 8.80$ & $47.4 I \pm 3.77$ & I.10* & .29 \\
\hline Anxiety ${ }^{\# \# \#}$ & $17.95 \pm 4.41$ & $17.00 \pm 2.00$ & $16.76 \pm 3.29$ & $18.91 \pm 3.47$ & $1.70 *$ & .21 \\
\hline Depression $^{s}$ & $14.20 \pm 3.23$ & $11.00 \pm 3.20$ & $13.85 \pm 3.75$ & $15.58 \pm 3.34$ & $3.24 * *$ & .10 \\
\hline Behavior control $^{\$}$ & $15.94 \pm 2.86$ & $15.66 \pm 2.12$ & $15.96 \pm 2.82$ & $17.83 \pm 2.55$ & I.73* & .17 \\
\hline Positive affect ${ }^{\$}$ & $17.24 \pm 3.65$ & $17.00 \pm 3.35$ & $17.29 \pm 3.58$ & $15.91 \pm 3.55$ & 0.51 & .10 \\
\hline
\end{tabular}

\#Relationship Dynamics Scale, \#\#Revised UCLA Loneliness Scale, \#\#\#Mental Health Inventory, \$Mental Health Inventory, ${ }^{* p}<0.05$, ** $p<0.01$, ANOVA.

TABLE VI: LINEAR REGRESSION OF RELATIONSHIP DYNAMICS ON MENTAL HEALTH COMPONENTS $(\mathbf{N}=150)$

\begin{tabular}{|c|c|c|c|c|c|c|c|c|}
\hline \multirow{2}{*}{ Variables } & \multicolumn{2}{|c|}{ Anxiety } & \multicolumn{2}{|c|}{ Depression } & \multicolumn{2}{|c|}{ Behavior Control } & \multicolumn{2}{|c|}{ Positive Affect } \\
\hline & B & $95 \% \mathrm{Cl}$ & B & $95 \% \mathrm{Cl}$ & B & $95 \% \mathrm{Cl}$ & B & $95 \% \mathrm{Cl}$ \\
\hline Constant & 27.02 & {$[24.74,29.29]$} & 17.10 & {$[14.56,19.64]$} & 18.69 & {$[16.66,20.72]$} & 20.92 & {$[18.35,23.49]$} \\
\hline Relationship Dynamics & -.632 ** & {$[-.780,-.484]$} & $-.208^{*} *$ & {$[-.373,-.042]$} & $-.174 *$ & {$[-.306,-.042]$} & $-.252 * *$ & {$[-.419,-.085]$} \\
\hline $\mathrm{R}^{2}$ & & 0.325 & & 0.040 & & 0.044 & & 0.057 \\
\hline $\mathrm{F}$ & & 71.11 & & 6.16 & & 6.79 & & 8.88 \\
\hline
\end{tabular}

TABLE VII: LINEAR REGRESSION ANALYSIS OF ISOLATION ON MENTAL HEALTH COMPONENTS (N = I50)

\begin{tabular}{|c|c|c|c|c|c|c|c|c|}
\hline \multirow{2}{*}{ Variables } & \multicolumn{2}{|c|}{ Anxiety } & \multicolumn{2}{|c|}{ Depression } & \multicolumn{2}{|c|}{ Behavior Control } & \multicolumn{2}{|c|}{ Positive Affect } \\
\hline & B & $95 \% \mathrm{Cl}$ & B & $95 \% \mathrm{Cl}$ & B & $95 \% \mathrm{Cl}$ & B & $95 \% \mathrm{Cl}$ \\
\hline Constant & 27.15 & {$[24.27,30.03]$} & 16.77 & {$[13.72,19.81]$} & 21.41 & {$[19.12,23.71]$} & 24.91 & {$[22.05,27.77]$} \\
\hline Isolation & $-.196^{*}$ & {$[-.253,-.138]$} & -.057 & {$[-.117, .004]$} & -.108 & {$[-.154, .063]$} & $-.158^{*}$ & {$[-.215,-.101]$} \\
\hline $\mathrm{R}^{2}$ & \multicolumn{2}{|r|}{0.234} & \multicolumn{2}{|r|}{0.022} & \multicolumn{2}{|r|}{0.128} & \multicolumn{2}{|r|}{0.168} \\
\hline $\mathrm{F}$ & \multicolumn{2}{|r|}{45.11} & \multicolumn{2}{|r|}{3.37} & \multicolumn{2}{|r|}{21.78} & \multicolumn{2}{|r|}{29.78} \\
\hline
\end{tabular}

$\mathrm{Cl}=$ confidence interval, $\mathrm{B}=$ Beta Coefficient, ${ }^{*} \mathrm{p}<0.05$

and found these women were experiencing isolation and suffering from depression, anxiety and guilt issues. It was revealed that lack of social support and increase in relation dynamics is a common issue among infertile couples, which ultimately leads to isolation, and mental health issues. ${ }^{17}$
Pakistani research by Hassan et $\mathrm{al}^{18}$ highlighted that low marital satisfaction, non-working status, high desire to have child have significant effect on psychological distress. Furthermore, low social support from mother in law, higher desire of husband for the child has significant effect on decreasing martial satisfaction. Other factors such as criticism, isolation, regular fights, and stressful home condition were major cause of increasing depression, anxiety among infertile women. ${ }^{19,20}$

As it has been discussed that infertility rate is increasing and affecting couples 
globally. It is important to explore this phenomenon in greater depth and create awareness in couples regarding the causes and consequences of infertility. For that purpose, the present study was designed specifically to investigate the relation between relationship dynamics, isolation and mental health. The second objective of the study was to explore the effect of different demographics like menstrual issues, history of miscarriage, and infertility issues on study variables. The last objective of the study was to explore the predictive effect of relationship dynamics and isolation on mental health of infertile women. It will be helpful to fill gaps in the literature and will help doctors, family/couple therapists to grasp more understanding and more awareness about issues, which were not reported before. It will open new domains for research in future.

\section{METHODS}

This correlational research design was conducted on pregnant women from January 2018 to December 2018. A sample of 150 infertile women was taken through purposive sampling from Alshifa Maternity Care Rawalpindi, Alshifa Hospital, Benazir Bhutto Hospital Rawalpindi, Fauji Foundation Hospital Rawalpindi and Pakistan Institute of Medical Sciences Islamabad, Pakistan.

The sample was determined using Solvin's formula $\left(n=N \div\left(I+N^{2}\right)\right.$ with an error level of 0.05 . Infertile women in the age range of 18 to 50 years, living with their husbands, having at least two years of marriage and had a history of miscarriage or experiencing infertility issues were included in this study. Whereas women using birth control techniques were excluded from the sample. All the samples were taken in person from the selected infertility centers for which prior permission was taken from Institutional Ethical Committee of Foundation University, Rawalpindi. All the ethical considerations including ensuring confidentiality and maintaining anonymity of the participants were ensured in study.
After fulfilling the inclusion and exclusion criteria, the selected participant completed three instruments in form of a booklet that was handed over to them. The first scale was the Relationship Dynamics Scale $(\mathrm{RDS})^{21}$ consisted of 8 items; this scale is a 3 point Likert scale with responses ranges from I=Almost never, 2 = Once in a while, $3=$ Frequently. The minimum score of the scale is 8 and maximum score is 24 where high score indicates conflicting relationship among the couples. The reliability of RDS was found to be $(\alpha=.80){ }^{21}$ The second scale used in present study was Revised UCLA Loneliness Scale (RULS) which was developed by Peplau \& Cutrona. ${ }^{22}$ The scale consist of 20 items that measures the feeling of loneliness/ isolation. The scale consists of 10 negatively phrased items and 10 positive phrased items. The RULS is four point Likert scale with score ranges are ( $1=$ Never, $2=$ Rarely $3=$ Sometimes, $4=$ Often). The scale score ranges are 20-80 whereas score below " 40 " shows minimum isolation feelings and scores above "40" shows feeling of isolation. The reliability of RULS was found to be $\alpha=.94 .^{22}$ Mental Health Inventory (MHI- 18$)^{23}$ measures overall positive and negative emotional functioning of the individual. It contains 18 items with 4 subscales namely e.g., anxiety, depression, behavioral control and positive affect. The subscale and total scores range from 18-108, the higher score on the scale show better mental health. The scale consists of 8 items that are reverse scores item. The overall reliability of MHI-I8 is found to be $\alpha=.93$. $^{23}$

Data collected was further analyzed using SPSS version 21.0. Correlation was carried out for study variables. Ttest was analyzed for menstrual cycle and history of miscarriage. ANOVA was carried out year of treatment and gynecological issues. Lastly, linear regression analysis was carried out to explore the predictive relationship dynamics and isolation on mental health of infertile women.

\section{RESULTS}

Out of infertile women, 48 (32\%) were ranging in age from 18-28 years, 74 (49.3\%) were from $29-39$ years and 28 (18.7\%) were $\geq 40$ years of age. Seventy-two $(48.0 \%)$ women belonged to nuclear and $78(52.0 \%)$ were from joint family structure. Majority of women $(n=104 ; 69.3 \%)$ belonged to urban areas and $46(30.7 \%)$ belonged to rural areas. Forty-seven (31.3\%) women had duration of marriage as $3-5$ years, 74 (49.3\%) had 6-8 years and 29 (19.3\%) women had $\geq 9$ years duration of marriage. Monthly income of the families was Rs. 30,000 50,000 in 20 (13.3\%) cases, Rs. 5I,00080,000 in $118(78.7 \%)$ cases and more than 80,000 rupees in 12 (8\%) cases.

As per Table I, relationship dynamics had positive strong correlation with isolation $(r=.525, p<.01)$, whereas negative strong correlation was recorded with anxiety $(r=-.570$, $p<.0 \mathrm{l})$, depression $(r=-.200 . p<.05)$, behavior control $(r=-.210, p<.05)$, and positive affect $(r=-.238 . p<.0 \mathrm{I})$. Isolation has negative strong correlation with anxiety $(r=-.438, p<.0 \mathrm{I})$, depression $(r=-.149)$, behavior control $(r=-.358, p<.01)$, and positive affect $(r=-.409, p<.01)$.

In Table II, infertile women having menstrual cycle issues had higher means of relationship dynamics ( $15.73 \pm 2.80)$, isolation $(49.78 \pm 7.43)$ and behavior control (16.59 \pm 2.59$)$. Infertile women with no menstrual cycle issues had higher means of anxiety $(18.11 \pm 4.06)$ and depression (14.15 13.04$)$. The Cohen's size show the strong size effect of study variables on demographic variable.

In Table III, infertile women having history of miscarriage had higher means of relationship dynamics ( $15.63 \pm 3.37)$ and isolation (49.73 \pm 7.76$)$. Infertile women having no history of miscarriage are higher on depression (14.43 \pm 3.42$)$, behavior control (16.17 \pm 2.98$)$, positive affect(I7.28 \pm 3.62$)$. Table IV shows higher means in women with more year of treatment for relationship dynamics, anxiety, depression, behavioral control. In contrast, women with recent treatment procedure had higher means of positive effect. The Cohen's strong size shows the size effect of study variables on demographic variable. 
Table $V$ shows that the infertile women with uterus issue are higher on relationship dynamics $(16.16 \pm 3.18)$, isolation (50.87 \pm 8.80$)$, and positive affect $(17.29 \pm 3.58)$. Infertile women with tube issues are higher on anxiety mean $(18.91 \pm 3.47)$, depression mean (I5.58 \pm 3.34$)$ and behavioral control mean $(17.83 \pm 2.55)$ as compare to other gynecological issues.

Regression analysis showed that relationship dynamic was negatively significant predictor of anxiety, $(\beta=-$ $0.570, \mathrm{p}<0.00 \mathrm{I})$, depression $(\beta=-$ $0.200, p<0.001)$, behavioral control $(\beta$ $=-0.210, \mathrm{p}<0.00 \mathrm{I})$, and positive affect $(\beta=-0.238, p<0.00 \mathrm{I})$ and explained $32.5 \%$ variance in anxiety, $4 \%$ variance depression, explained a total of $4.4 \%$ variance in behavior control and a total of $5.7 \%$ variance in positive affect as shown in Table VI.

Regression analysis in Table VII further revealed that isolation negatively predicted anxiety $(\beta=-0.483$, $p<0.00 \mathrm{I})$, depression $(\beta=-0.149$, $\mathrm{p}<0.00 \mathrm{I})$, behavioral control $(\beta=-$ $0.358, p<0.00 \mathrm{I})$, and positive affect $(\beta=-0.409, p<0.00 I)$. The value of $R^{2}$ showed that isolation explained a total of $23.4 \%$ variance in anxiety, a total of $2.2 \%$ variance in depression, a total of $12.8 \%$ variance in behavior control and a total of $16.8 \%$ variance in positive affect.

\section{DISCUSSION}

The present study was conducted to explore the effect of relationship dynamics and isolation on mental health of infertile women. It was predicted that socially isolated infertile women having relationship dynamics would have greater risks of developing mental health issues such as anxiety, guilt, depression and other behavioral issues. Moreover, infertile women are also more likely to face relationship distress with their partner which may insert negative influence on their mental health. ${ }^{11,12}$ One of the largest study on infertility containing sample of 352 women and 274 men was collected from infertility centers of northern California. The study revealed that $56 \%$ of the women and $32 \%$ of the men experienced symptoms of depression whereas; anxiety symptoms existed in $76 \%$ of the women and $61 \%$ of the men. ${ }^{14}$

The result further revealed that women with menstrual issues, having history of miscarriages, and with more year of treatment were higher on relationship dynamics, isolation, anxiety, depression, and behavioral control. The current study is in support of the previous literature which have highlighted that the relationship dynamics in the context of infertility leads to isolation. ${ }^{12,13}$ The infertile women with behavior control were found to be higher on depression.

${ }^{15-17}$ As the social pressure and treatment procedure put lot of stress on already stressed women with higher pressure from in-laws. Another indigenous by Hassan et al $^{18}$ have supported the research findings that low marital satisfaction, non-working status, high desire to have child have significant effect on psychological distress. Furthermore, low social support from mother in law, higher desire of husband for the child has significant effect on decreasing marital satisfaction. Other factors such as criticism, isolation, regular fights, and stressful home condition were major cause of increasing depression, anxiety among infertile women. ${ }^{19,20}$

Finally the present study also found significant effect of relationship dynamic and isolation on mental health (e.g., anxiety, depression, behavioral control and positive affect) and among infertile women. As per previous investigation ${ }^{20-}$ ${ }^{23}$ infertile couples experience higher depression and anxiety than the fertile couples. Women's experience with infertility creates a negative impact on her overall mental health of infertile women. Recent study by $\mathrm{Xu}$ et $\mathrm{al}^{15}$ revealed that disruption in relationship and social isolation is more likely to happen in the lives of infertile people. Lynch et a ${ }^{16}$ investigated infertility crisis in women and found these women were experiencing isolation and suffering from depression, anxiety and guilt issues. As lack of social support and increase in relation dynamics is a common issue among infertile couples which ultimately leads to isolation and mental health issues. ${ }^{16,18,25}$ Although the individual reactions to infertility may vary to a great deal, however, many studies have documented certain specific common reactions such as depression, avoidance, anxiety, guilt etc. among infertile couples across cultures. Moreover, lack of social support, isolation and emotional and relationship distress are the common factors which are faced by infertile couples which consequently influence their mental health. Many of the previous researches have shown that infertile couples who have lack of social support and experience more relationship distress experience less behavior and emotional control and more mental health issues. ${ }^{20,27}$

\section{CONCLUSION}

The results of the study summarized that most of the infertile women experienced strong isolation and depression emotions. The study concluded that improved relationship dynamics helped to decrease depression, anxiety, behavior control and positive affect among infertile women. The research also highlighted that lower feeling of isolation in infertile women increased mental health of the infertile women. Overall research findings highlighted that improving relationship dynamics decreased isolation feeling and then in turn improved the mental health of the infertile women. It can be concluded from current research findings that improving the relationship circumstances among the infertile women by guidance of gynecologist, medical professional and clinical psychologist helped to decrease the emotional distress and wellness among infertile women.

\section{REFERENCES}

I. Antle B, Sar B, Christensen D, Karam E, Ellers F, Barbee A, et al. The impact of the within my reach relationship training on relationship skills and outcomes for low-income individuals. J Marital Fam Ther 20I3;39(3):346-57. DOI: 10 . I I I I/j. I752-0606.20I2.003|4.x.

2. Hawkley LC, Cacioppo JT. Loneliness matters: A theoretical and empirical review of 
consequences and mechanisms. Ann Behav Med 2010;40(2): 218-27. DOI:10.1007/s 12160$010-9210-8$

3. World Health Organization (WHO). Mental Health Organization. A state of well-being;2019. [Accessed on: August 10, 2019]. Available from URL: https://www.who.int/ features/factfiles/mental_health/en/

4. De-Berardis D, Mazza M, Marini S, Nibletto LD, SerroniN, Pino MC, et al. Psychopathology, emotional aspects and psychological counselling in infertility: a review. Clin Ter 2014;165(3): 163-9. DOI: 10.74I7/CT.2014.1716.

5. Volgsten $\mathrm{H}$, Svanberg AS, Ekselius L, Lundkvist O, Poromaa IS. Prevalence of psychiatric disorders in infertile women and men undergoing in vitro fertilization treatment. Hum Reprod 2008; 23(9):2056-63. DOI: 10.1093/ humrep/den 154 .

6. Gurunath S, Pandian Z, Anderson RA, Bhattacharya S. Defining infertility: a systematic review of prevalence studies. Hum Reprod Update 20II;I7(5):575-88. DOI: 10.1093/humupd/dmr0I5.

7. Sudha G, Reddy KS. Causes of female infertility: a cross sectional study. Int J Latest Res Sci Tech 2013;2(6): 119-23.

8. Mascarenhas MN, Flaxman SR, Boerma T, Vanderpoel S, Stevens GA. National, regional, and global trends in infertility prevalence since 1990: a systematic analysis of 277 health surveys. PLoS Med 20I2;9(I2):350-56. DOI:I0.137|/ journal.pmed. I00।356.g005.

9. Cozaru GC, Butnariu LI, Gorduza EV. Genetic counselling in reproductive disorders. Procedia Soc Behav Sci 20I2; 33(I):213- 17. DOI:10.1016/j.sbspro.2012.01.114

10. Afifi WA, Falato WL, Weiner JL. Identity concerns following a severe relational transgression: The role of discovery method for the relational outcomes of infidelity. J Soc Pers Relat 200I;|8(2):29|-08. DOI:

\section{|0.| |77/026540750| |82007.}

II. Whisman MA, Uebelacker. Comorbidity of relationship distress and mental and physical health problems. In D. K. Snyder and M. A. Whisman (Eds.), Treating difficult couples: Helping clients with coexisting mental and relationship disorders. New York:Guilford Press; 2003. p. 3-26. [Accessed on: August 10, 2019]. Available from URL: https://psycnet.apa.org/ record/2004-000l3-00I.

12. Matthews T, Danese A, Wertz J, Odgers CL, Ambler A, Moffitt TE, et al. Social isolation, loneliness and depression in young adulthood: A behavioural genetic analysis. Soc Psychiatry Psychiatr Epidemiol 20I6;5I(3):339-48. DOI: 10.1007/ s00127-016-II78-7.

13. Holley SR, Pasch LA, Bleil ME, Gregorich S, Katz PK, Adler NE. Prevalence and predictors of major depressive disorder for fertility treatment patients and their partners. Fertil Steril 2015; 103(5):1332-9. DOI: 10.1016/ j.fertnstert.2015.02.018.

14. Pasch LA, Holley SR, Bleil ME, Shehab D, Katz PP, Adler NE. Addressing the needs of fertility treatment patients and their partners: are they informed of and do they receive mental health services? Fertil Steril 2016; 106(I):209-I5. DOI: 10.1016/j.f ertnstert.2016.03.006.

15. Xu H, Ouyang N, Li R, Tuo P, Mai M, Wang $W$. The effects of anxiety and depression on in vitro fertilization outcomes of Chinese women. Psychol Health Med 20 17;22(I):3743. DOI: $10.1080 / 13548506.2016$. 1218031 .

16. Lynch CD, Sundaram R, Maisog JM, Sweeney AM, Buck Louis GM. Preconception stress increases the risk of infertility: results from a couple-based prospective cohort study--the LIFE study. Hum Reprod 20|4;29(5): I067- 75. DOI: 10. 1093/humrep/deu032.

17. Sejbaek CS, Hageman I, Pinborg A, Hougaard CO, Schmidt L. Incidence of depression and influence of depression on the number of treatment cycles and births in a national cohort of 42880 women treated with ART. Hum Reprod 2013;28(4): I I00-9. DOI: 10.1093/ humrep/des 442 .

18. Hassan S, Khurshid E, Batool B. Psychological distress experienced by women with primary infertility in Pakistan: role of psycho-social and cultural factors. NUST J Soc Scien Human 20I5; I (2):56-72.

19. Shaheen R, Subhan S, Sultan S, Subhan K, Tahir S. Prevalence of infertility in a cross section of Pakistani population. Pak J Zoo 2010;42(4);389-93.

20. Sultan S. Marital Discord: The Hidden Burden of Infertility. Pak J Psychol Res 2010;25(I);31-43.

21. Scott S, Markman H. Marriage in the 90s: A nationwide random phone survey. Denver, CO: PREP Inc; 1997. [Accessed on: August 10, 2019]. Available from URL: https://healthymarriageandfamilies. org/library-resource/marriage-90snationwide-random-phone-survey.

22. Russell D, Peplau LA, Cutrona CE. The Revised UCLA Loneliness Scale: Concurrent and discriminate validity evidence. J Pers Soc Psychol 1 980;39(3):472-80. DOI: |0.|037//0022-35|4.39.3.472.

23. Veit CT, Ware JE. The structure of psychological distress and wellbeing in general populations. J Consult Clin Psychol 1983;5 I (5):730-42. DOI: 10.1037//0022$006 \times .51 .5 .730$.

24. Schwerdtfeger KL, Shreffler KM. Trauma of pregnancy loss and infertility for mothers and involuntarily childless women in the contemporary United States. J Loss Trauma 2009; I4(3):2II-27. DOI: 10.1080/I5325020802537468.

25. Rooney KL, Domar AD. The relationship between stress and infertility. Dialogues Clin Neurosci 20I8; 20(I): 4I-7.

26. Negro-Vilar A. Stress and other environmental factors affecting fertility in men and women: overview. Environ Health Perspect 
Suppl 1993; I0I(2):59-64. DOI:

I0.1289/ehp.9310Is259.
27. Sami N, Saeed AT, Wasim S, Saleem S. Risk factors for secondary infertility among women in Karachi,
Pakistan. PLoS One 20I2;7(4):2835. DOI: $10.137 \mid$ /journal. pone. 0035828 .

\section{AUTHORS' CONTRIBUTIONS}

Following authors have made substantial contributions to the manuscript as under:

RZM: Conception \& study design, analysis and interpretation of data, drafting the manuscript, final approval of the version to be published

SZ: Acquisition, analysis and interpretation of data, critical revision, final approval of the version to be published

SE: Acquisition, analysis and interpretation of data, critical revision, final approval of the version to be published

Authors agree to be accountable for all aspects of the work in ensuring that questions related to the accuracy or integrity of any part of the work are appropriately investigated and resolved

\section{CONFLICT OF INTEREST}

Authors declared no conflict of interest GRANT SUPPORT AND FINANCIAL DISCLOSURE NIL
DATA SHARING STATEMENT

The data that support the findings of this study are available from the corresponding author upon reasonable request

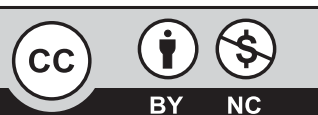

BY NC
This is an Open Access article distributed under the terms of the Creative Commons Attribution-Non Commercial 2.0 Generic License.

KMUJ web address: www.kmuj.kmu.edu.pk

Email address: kmuj@kmu.edu.pk 